\title{
EDITORIAL
}

\section{Vitamin D in asthma and allergy: what next?}

\author{
S.T. Weiss and A.A. Litonjua
}

$\mathbf{M}$ uch of the original work on vitamin D and asthma incidence focused on birth cohort studies. These studies examined the effect of maternal intake of vitamin D during pregnancy and its impact on asthma/wheeze in the first few years of life [1-3]. In all three of these methodologically wellperformed birth cohort studies, higher maternal intake of vitamin $\mathrm{D}$ was associated with a lower incidence of asthma and wheeze in the child. However, one cohort study with very a small sample size and high loss to follow-up may have obtained spurious negative results as a consequence of these significant methodological flaws [4]. Another relevant concern is that the positive studies did not measure vitamin $\mathrm{D}$ directly but simply looked at maternal vitamin D intake, mostly from supplements, as a proxy for vitamin D levels.

This brings us to the study by HolLams et al. [5] in this issue of the European Respiratory Journal, which looked at 989 6-yr-olds and 1,380 14-yr-olds from an unselected birth cohort in Perth, Australia. Of the Raine cohort participants, 689 subjects were seen longitudinally at both ages 6 and $14 \mathrm{yrs}$, and the predictive value of vitamin D levels at age 6 yrs could be used to assess clinical outcomes at age 14 yrs. Loss to follow-up, the major validity threat in a study such as this, was demonstrated not to influence their results. Vitamin D levels at ages 6 and $14 \mathrm{yrs}$ were predictive of allergy/asthma outcomes at that age. But more importantly, vitamin D levels at age 6 yrs were predictive of subsequent atopy/asthma-associated phenotypes at age 14 yrs. The significant results were restricted to males. This study is the first to demonstrate such an association, as seen in the early-life birth cohort studies, in older children and is one of the first using vitamin D levels as a biomarker of vitamin D exposure.

What about serum Vitamin D levels as a biomarker, particularly as it pertains to asthma? This question needs to be broken up into several parts. First, what is an adequate serum level of vitamin D? There is a great deal of controversy as to what represents adequate levels of vitamin $\mathrm{D}$ in the blood for human health generally, let alone for asthma specifically [6-8]. There is a greater number of studies in the medical literature in which vitamin D levels have been measured in prevalent asthma cases rather than in population samples of predominantly normal subjects [9-12]. That having been noted, we would agree that $>75 \mathrm{nmol} \cdot \mathrm{L}^{-1}\left(>30 \mathrm{ng} \cdot \mathrm{mL}^{-1}\right)$ is sufficient while $50-75 \mathrm{nmol} \cdot \mathrm{L}^{-1}$

Channing Laboratory, Brigham and Women's Hospital, Boston, MA, USA.

CORRESPONDENCE: S.T. Weiss, Channing Laboratory, Harvard School of Medicine, 181 Longwood Ave, Boston, MA 02115, USA. E-mail: scott.weiss@channing.harvard.edu $\left(20-30 \mathrm{ng} \cdot \mathrm{mL}^{-1}\right)$ is insufficient and $<50 \mathrm{nmol} \cdot \mathrm{L}^{-1}$ or $<20 \mathrm{ng}$. $\mathrm{mL}^{-1}$ is deficient. Using these criteria, $41.4 \%$ of the children in the Raine cohort had sufficient vitamin D levels at age $14 \mathrm{yrs}$ during the winter months. This is actually substantially higher than many other populations, and may relate to the greater time spent outdoors in the temperate climate of Western Australia. In many western populations, the prevalence of insufficiency is $>70 \%[13,14]$ and varies by season of the year, making it impossible to perform such a study as that of Hollams et al. [5].

The second part of the question is methodological. How good a biomarker is serum vitamin $\mathrm{D}$ ? The Raine investigators took advantage of two methodological features of their data and their data analysis. First, they utilised vitamin D as a continuous variable to obtain maximal power and secondly, they had an unusually high correlation between the age 6 yrs and the age 14 yrs serum vitamin $D$ levels $(r=0.93)$. In most investigations of serial vitamin D levels, the r-value (correlation) between two subsequent serum vitamin $\mathrm{D}$ values taken about 3 months to $1 \mathrm{yr}$ apart is $\sim 0.4$, similar to what one might find for low-density lipoprotein cholesterol. This is reflective of the high degree of variability in vitamin $\mathrm{D}$ measurements due to environmental, metabolic and genetic factors. Environmental factors influencing vitamin D levels include sun exposure, sun screen use, time spent outdoors, diet and season of the year. Only season of the year was actually measured by HolLAMS et al. [5], but $95 \%$ of all subjects were Caucasian (controlling for skin colour) and perhaps controlling for season was critical. Alternatively, the other potential environmental variables must not have changed over the 8 yrs of the study. This is a most remarkable finding since in most studies, a biomarker such as vitamin $\mathrm{D}$ will be only weakly predictive over such a long period of time due to the low correlation on repeat measurement and subsequent misclassification of exposure.

As noted by HolLAms et al. [5], the authors had no information on children at birth or in the first few years of life in the time frame of the early birth cohort studies noted above [1-3]. Fortunately, there are some observational data that can be brought to bear on this age group. CAMARGO JR et al. [15] noted that $27 \%$ of New Zealand infants would be in the range of sufficiency (e.g. levels $>75 \mathrm{nmol} \cdot \mathrm{L}^{-1}$ ) based on cord blood vitamin D levels. Those authors then found that lower cord blood levels of vitamin $\mathrm{D}$ were predictive of respiratory illness at age 3 months and of wheezing at 15 months, 3 yrs and 5 yrs of age. While CAMARGo JR et al. [16] make a point of emphasising a lack of association of cord blood levels with asthma at age $5 \mathrm{yrs}$, this seems less relevant given the low predictive power of a single measure of vitamin $\mathrm{D}$ as a biomarker and the 
small number of sufficient subjects at birth in this study. This work would tend to confirm the paper by HoLLAMs et al. [5] for an early life birth cohort.

Mechanistically, vitamin D exerts its effects in asthma through both immune and structural effects in the developing fetal and perhaps post-natal lung. These effects are extensively reviewed elsewhere [17-19]. Recently, the role of vitamin D as a modulator of the infant intestinal microbiome has also been suggested as another potential mechanism involved in asthma and other autoimmune disease pathogenesis [20]. All of this mechanistic work is strengthened by the epidemiology presented by Hollams et al. [5] and CAMARGo Jr et al. [16].

Another interesting aspect of the study by HolLAMs et al. [5] is the finding that their results pertained to males but not females. They note that there is a functional synergy between 1,25hydroxyvitamin $\mathrm{D}_{3}$ and 17- $\beta$-oestradiol, mediated through oestrogen receptor $\alpha$, to enhance vitamin D receptor expression, inactivate vitamin D catabolism (CYP24A1) and increase vitamin $\mathrm{D}_{3}$-binding protein. We would note that for a given height and age, females have more body fat than men and that vitamin $\mathrm{D}$ is a fat-soluble vitamin, so these compensatory mechanisms may be evolutionarily important given the important role of vitamin D in fertility and conception [21-24]. Whether these biological mechanisms explain the results or whether they are due to small sample size, further exploration of the evolutionary adaptions to low vitamin D exposure in pregnancy is a worthwhile scientific endeavour. It is worth noting that, consistent with the animal data and basic research, different observational human studies have shown effects of vitamin D on allergy phenotypes, asthma/wheeze, lung function, airway responsiveness and bronchodilator response but never have these effects been present in every study. Vitamin D levels, length of follow-up, age, sample size and myriad other factors influence which of these phenotypes are most significant in an individual investigation.

At the end of the day, all of the studies cited here are observational and hence are subject to multiple potential biases, such as loss to follow-up, small sample size [4] or recall and information bias [25]. Given our lack of knowledge about the optimal dose of vitamin D for immune system functioning, the variability of vitamin $\mathrm{D}$ as a biomarker, and the very high prevalence of vitamin D insufficiency in western industrial populations, clinical trial results are needed to make definitive recommendations for both asthma prevention and for the use of vitamin D with inhaled corticosteroids to prevent steroid resistance. Fortunately, such trials for asthma prevention (www.clinicaltrials.gov identifiers NCT00920621 and NCT00 856947), for enhancing steroid effectiveness in established disease (NCT01248065) or for prevention of exacerbations (NCT00978315) are under way. One of the debates that will occur, should the prevention trials show positive benefit, is the relative role of the protective effect of vitamin D with maternal pregnancy versus post-natal supplementation. It seems highly unlikely that maternal supplementation to sufficiency during pregnancy alone will, by itself, prevent asthma and allergic phenotypes; some degree of post-natal supplementation will also probably be necessary to maintain normal immune function in the long term.

\section{STATEMENT OF INTEREST}

None declared.

\section{REFERENCES}

1 Camargo CA Jr, Rifas-Shiman SL, Litonjua AA, et al. Maternal intake of vitamin $\mathrm{D}$ during pregnancy and risk of recurrent wheeze in children at 3 y of age. Am J Clin Nutr 2007; 85: 788-795.

2 Devereux G, Litonjua AA, Turner SW, et al. Maternal vitamin D intake during pregnancy and early childhood wheezing. Am J Clin Nutr 2007; 85: 853-859.

3 Erkkola M, Kaila M, Nwaru BI, et al. Maternal vitamin D intake during pregnancy is inversely associated with asthma and allergic rhinitis in 5-year-old children. Clin Exp Allergy 2009; 39: 875-882.

4 Gale CR, Robinson SM, Harvey NC, et al. Maternal vitamin D status during pregnancy and child outcomes. Eur J Clin Nutr 2008; 62: 68-77.

5 Hollams EM, Hart PH, Holt BJ, et al. Vitamin D and atopy and asthma phenotypes in children: a longitudinal cohort study. Eur Respir I 2011; 38: 1320-1327.

6 Ross AC, Manson JE, Abrams SA, et al. The 2011 report on dietary reference intakes for calcium and vitamin D from the Institute of Medicine: what clinicians need to know. J Clin Endocrinol Metab 2011; 96: 53-58.

7 Heaney RP, Holick MF. Why the IOM recommendations for vitamin D are deficient. J Bone Miner Res 2011; 26: 455-457.

8 Holick MF. The IOM D-lemma. Public Health Nutr 2011; 14: 939-941.

9 Brehm JM, Celedón JC, Soto-Quiros ME, et al. Serum vitamin D levels and markers of severity of childhood asthma in Costa Rica. Am J Respir Crit Care Med 2009; 179: 765-771.

10 Brehm JM, Schuemann B, Fuhlbrigge AL, et al. Serum vitamin D levels and severe asthma exacerbations in the Childhood Asthma Management Program study. J Allergy Clin Immunol 2010; 126: 52-58.

11 Chinellato I, Piazza M, Sandri M, et al. Serum vitamin D levels and exercise-induced bronchoconstriction in children with asthma. Eur Respir J 2011; 37: 1366-1370.

12 Searing DA, Zhang Y, Murphy JR, et al. Decreased serum vitamin $\mathrm{D}$ levels in children with asthma are associated with increased corticosteroid use. J Allergy Clin Immunol 2010; 125: 995-1000.

13 Zgaga L, Theodoratou E, Farrington SM, et al. Diet, environmental factors, and lifestyle underlie the high prevalence of vitamin D deficiency in healthy adults in Scotland, and supplementation reduces the proportion that are severely deficient. J Nutr 2011; 141 $1535-1542$.

14 Ginde AA, Liu MC, Camargo CA Jr. Demographic differences and trends of vitamin D insufficiency in the US population, 1988-2004. Arch Intern Med 2009; 169: 626-632.

15 Camargo CA Jr, Ingham $\mathrm{T}$, Wickens $\mathrm{K}$, et al. Vitamin D status of newborns in New Zealand. Br J Nutr 2010; 104: 1051-1057.

16 Camargo CA Jr, Ingham $\mathrm{T}$, Wickens $\mathrm{K}$, et al. Cord-blood 25hydroxyvitamin D levels and risk of respiratory infection, wheezing, and asthma. Pediatrics 2011; 127: e180-e187.

17 Litonjua AA, Weiss ST. Is vitamin D deficiency to blame for the asthma epidemic? J Allergy Clin Immunol 2007; 120: 1031-1035.

18 Weiss ST, Litonjua AA. The in utero effects of maternal vitamin D deficiency: how it results in asthma and other chronic diseases. Am J Respir Crit Care Med 2011; 183: 1286-1287.

19 Lange NE, Litonjua A, Hawrylowicz CM, et al. Vitamin D, the immune system and asthma. Expert Rev Clin Immunol 2009; 5: 693-702.

20 Weiss ST. Bacterial components plus vitamin D: the ultimate solution to the asthma (autoimmune disease) epidemic? J Allergy Clin Immunol 2011; 127: 1128-1130. 
21 Blomberg Jensen M, Bjerrum PJ, Jessen TE, et al. Vitamin D is positively associated with sperm motility and increases intracellular calcium in human spermatozoa. Hum Reprod 2011; 26 1307-1317.

22 Sun $\mathrm{W}$, Xie H, Ji J, et al. Defective female reproductive function in $1,25(\mathrm{OH}) 2 \mathrm{D}$-deficient mice results from indirect effect mediated by extracellular calcium and/or phosphorus. Am J Physiol Endocrinol Metab 2010; 299: E928-E935.
23 Ozkan S, Jindal S, Greenseid K, et al. Replete vitamin D stores predict reproductive success following in vitro fertilization. Fertil Steril 2010; 94: 1314-1319.

24 Yuen AW, Jablonski NG. Vitamin D: in the evolution of human skin colour. Med Hypotheses 2010; 74: 39-44.

25 Hyppönen E, Sovio $\mathrm{U}$, Wjst $\mathrm{M}$, et al. Infant vitamin D supplementation and allergic conditions in adulthood: northern Finland birth cohort 1966. Ann NY Acad Sci 2004; 1037: 84-95. 